\section{(2) \\ BRAZIILIAN JOURNAL \\ OF MEDICAL AND BIOLOGICAL RESEARCH}

www.bjournal.com.br
ISSN 0100-879X

Volume 45 (3) 179-290 March 2012

BIOMIEDICAL SCIENCES

AND

CLINICAL INVESTIGATION

Braz J Med Biol Res, March 2012, Volume 45(3) 238-243

doi: 10.1590/S0100-879X2012007500021

Anxiolytic effects of repeated treatment with an essential oil from

Lippia alba and (R)-(-)-carvone in the elevated T-maze

V.Y. Hatano, A.S. Torricelli, A.C.C. Giassi, L.A. Coslope and M.B. Viana

The Brazilian Journal of Medical and Biological Research is partially financed by

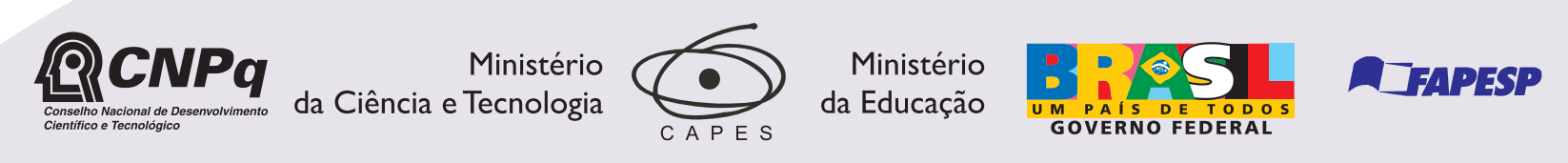

Institutional Sponsors

scielo
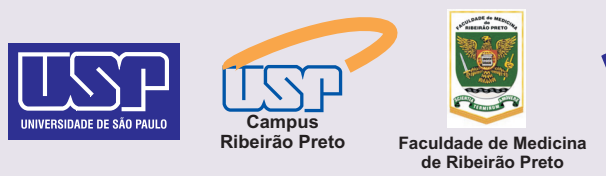

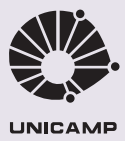

UNICAMP $\oplus$ SHIMADZU

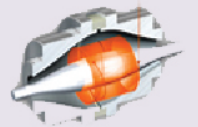

1DI Associaçāo Explore High - Performance MS Orbitrap Technology In Proteomics \& Metabolomics analitica $\underset{\text { analiticaweb.com.br }}{\text { Thermo }}$ 


\title{
Anxiolytic effects of repeated treatment with an essential oil from Lippia alba and (R)-(-)-carvone in the elevated T-maze
}

\author{
V.Y. Hatano ${ }^{1}$, A.S. Torricelli ${ }^{1}$, A.C.C. Giassi ${ }^{2}$, L.A. Coslope ${ }^{3}$ and M.B. Viana ${ }^{1}$ \\ ${ }^{1}$ Departamento de Biociências, Universidade Federal de São Paulo, Santos, SP, Brasil \\ ${ }^{2}$ Cellular and Molecular Medicine, University of Ottawa, Ottawa, Canada \\ ${ }^{3}$ Parque Nacional da Chapada Diamantina, Chapada Diamantina, BA, Brasil
}

\begin{abstract}
Lippia alba (Mill.) N.E. Brown (Verbenaceae) is widely used in different regions of Central and South America as a tranquilizer. The plant's anxiolytic properties, however, merit investigation. The present study evaluated the effects of repeated daily (14 days) intraperitoneal (ip) treatment with an essential oil (EO) from a chemotype of L. alba (LA, chemotype II, 12.5 and 25 mg/ $\mathrm{kg} ; \mathrm{N}=6-8)$ and $(\mathrm{R})-(-)$-carvone $(25 \mathrm{mg} / \mathrm{kg} ; \mathrm{N}=8-12)$, the main constituent of this chemotype, on male Wistar rats (weighing $250 \mathrm{~g}$ at the beginning of the experiments) submitted to the elevated T-maze (ETM). The ETM allows the measurement of two defensive responses: inhibitory avoidance and one-way escape. In terms of psychopathology, these responses have been related to generalized anxiety and panic disorder, respectively. Treatment with the EO impaired ETM avoidance latencies, without altering escape, in a way similar to the reference drug diazepam $(P<0.05)$ (avoidance 2: control $=84.6 \pm 35.2 ; \mathrm{EO} 12.5 \mathrm{mg} / \mathrm{kg}$ $=11.8 \pm 3.8$; EO $25 \mathrm{mg} / \mathrm{kg}=14.6 \pm 2.7$; diazepam $=7 \pm 2.1)$. $(\mathrm{R})-(-)$-carvone also significantly altered this same response $(P$ $<0.05$; avoidance 1: control $=91.9 \pm 31.5$; carvone $=11.6 \pm 1.8$; diazepam $=8.1 \pm 3.3$ ). These results were not due to motor changes since no significant effects were detected in an open field. These observations suggest that LA exerts anxiolytic-like effects on a specific subset of defensive behaviors that have been implicated in generalized anxiety disorder, and suggest that carvone is one of the constituents of LA responsible for its action as a tranquilizer.
\end{abstract}

Key words: Lippia alba; Essential oil; Carvone; Anxiety; Elevated T-maze

\section{Introduction}

Lippia alba (Mill.) N.E. Brown Verbenaceae (LA) is an aromatic shrub, widely used in Central and South America for the treatment of different clinical conditions such as digestive, respiratory and cardiovascular disorders and as an antiseptic, analgesic and tranquilizer (1).

The results of experimental studies conducted with LA are generally consistent with its traditional uses. Thus, antibacterial and antifungal activities have been shown for different root and leaf extracts $(2,3)$ and antiviral activity was observed with an ethanol leaf extract (4). Also anxiolytic effects in the elevated plus-maze have been previously shown after acute ip administration to mice of essential oils (EOs) from two different chemotypes of LA (5) (chemotype I, two subtypes, i.e., subtype 1: $55 \%$ citral, $10 \% \beta$-myrcene and subtype 2: $64 \%$ citral, $12 \%$ limonene; chemotype II: $55 \%$ carvone, $23 \%$ limonene; doses ranging from $25-200$ $\mathrm{mg} / \mathrm{kg})(6)$.

However, tests with some of the isolated constituents (citral, myrcene and limonene, $25-200 \mathrm{mg} / \mathrm{kg}$, ip) of the three EOs showed inconsistent results. Although these constituents exhibited sedative activity when administered acutely to rats (muscle relaxation in the rota-rod, decreases in the number of rearings and groomings in the open-field, and potentiation of pentobarbital-induced sleeping time), they did not exhibit an anxiolytic effect in the elevated plus-maze, but rather a slight anxiogenic effect at higher doses (7). This inconsistency questions the relevance of any conclusion concerning the anxiolytic properties of LA (1). Therefore, further investigations on the plant's use as a tranquilizer are still warranted.

In this respect, it should be pointed out that, although important as a first step for the evaluation of the anxiolytic

Correspondence: M.B. Viana, Departamento de Biociências, Universidade Federal de São Paulo, Campus Baixada Santista, 11060-001 Santos, SP, Brasil. Fax: +55-11-3868-3203. E-mail: mviana@unifesp.br

Received November 19, 2011. Accepted February 1, 2012. Available online February 27, 2012. Published March 19, 2012. 
properties of LA, the above studies $(6,7)$ were performed with a single animal model, the elevated plus-maze. Even though the model is widely used, it has failed to detect the effect of non-benzodiazepine anxiolytics $(8,9)$. Some investigators have suggested that this may occur because the elevated plus-maze is a "mixed" animal model, that is, one that does not separate different types of fear/anxiety (8). According to the DSM-IV-TR classification of psychiatric disorders, clinical anxiety is a heterogeneous phenomenon, comprising distinctive pathological conditions, such as generalized anxiety disorder (GAD), panic and phobias - these conditions being unequally affected by pharmacological therapy. On this basis, there is a growing body of evidence suggesting that anxiety, as operationally defined in a given animal model, may differ from that generated in other models concerning its nature (if innate or learned), its response to the effects of drugs and environmental manipulations, and its underlying neural substrate (10). On the basis of this evidence, efforts have been made to validate experimental models specifically related to certain kinds of anxiety disorders (10). A model that measures behavioral responses particularly related to specific subtypes of anxiety is the elevated T-maze (ETM) (11-14).

Although derived from the elevated plus-maze, the ETM allows the measurement of two subtypes of anxietyrelated responses in the same rat, i.e., inhibitory avoidance and one-way escape. Compounds representative of three classes of anxiolytics, namely the agonist of benzodiazepine receptors diazepam (DZP), the serotonin (5-HT) 1Aagonist buspirone, and the nonselective 5-HT2 antagonist ritanserin, have been shown to selectively impair inhibitory avoidance while leaving one-way escape unchanged $(11,12)$. These results are compatible with the view that inhibitory avoidance is related to GAD. In contrast, the escape task is insensitive to different classes of anxiolytics and is impaired by chronic, but not acute administration of imipramine (13), clomipramine and fluoxetine (14), drugs that are used to treat panic disorder. As a result, one-way escape in the ETM has been used as an animal model of panic.

The purpose of the present study was to further investigate the anxiolytic properties of LA by using the ETM, a model that allows the measurement of two different anxiety-related responses, one associated with GAD and the other with panic disorder. Since some pharmacological compounds have been shown to ameliorate specific subtypes of anxiety disorders (or to alter particular types of behavioral responses) only after repeated treatment (13-15), this regimen of administration was chosen. In the present study, male Wistar rats were treated daily for 14 days (12.5 and $25 \mathrm{mg} / \mathrm{kg}$, ip) with chemotype II, and subsequently tested in the ETM (experiment 1 ). We also determined the effects of repeated treatment with (R)-(-)carvone, one of the main constituents of this chemotype, on the behavior of animals tested in the ETM (experiment 2 ). Among the main constituents of the three EOs previ- ously investigated (6), carvone was the only one not tested for anxiolysis. For both experiments, DZP was used as a positive control. In order to avoid confounding results due to treatment effects on locomotor activity, animals were also tested in an open field.

\section{Material and Methods}

\section{Animals}

Male Wistar rats (approximately $250 \mathrm{~g}$ ) bred in the animal house of Universidade de São Paulo, Ribeirão Preto Campus (experiment 1), or of Universidade Federal de São Paulo, Brazil (experiment 2), were housed 5-6 per cage until the ETM experiments. Room temperature was controlled $\left(23 \pm 1^{\circ} \mathrm{C}\right)$ and lights were kept on from 7:00 am to 7:00 pm. Food and water were available ad libitum. The present study was approved by the Ethics Committee for Animal Research of Universidade Federal de São Paulo (protocol No. 0252/11) and was performed in compliance with the recommendations of the Brazilian Society of Neuroscience and Behavior ( $\mathrm{SBNec}$ ), which are based on the US National Institutes of Health Guide for Care and Use of Laboratory Animals.

\section{Plant material}

LA was cultivated in the Medicinal Plant Garden and an exsiccate deposited in the Prisco Bezerra Herbarium of Universidade Federal do Ceará under No. 24.149. EO samples from the leaves of chemotype II were prepared by the Laboratory of Natural Products of the University.

\section{Essential oil}

Leaves $(1 \mathrm{~kg}$ ) from chemotype II were collected on the same day and at the same time from flowering plants. Samples were steam distilled for $1 \mathrm{~h}$. The EO was analyzed by GC:MS using a Hewlett-Packard 5971 instrument under the following conditions: column, dimethylpolysiloxane DB-1 fused-silica capillary column (30 m_0.25 mm); carrier gas, helium ( $1 \mathrm{~mL}: \mathrm{min})$; injector temperature, $35-180^{\circ} \mathrm{C}$ at $4^{\circ} \mathrm{C}$ :min, then $180-250^{\circ} \mathrm{C}$ at $10^{\circ} \mathrm{C}$ :min; mass spectrum electron impact, $70 \mathrm{eV}$. Individual components were identified by spectrometric analysis using two computer library MS searches, and Kovats indices as a preselection aid. Visual mass spectrum comparison data from the literature were used for confirmation.

\section{Compound preparations}

EO from chemotype II, (R)-(-)-carvone (Sigma, USA) and DZP (Sigma) were suspended in saline with $2 \%$ Tween 80 . Control animals were injected with a vehicle solution (saline containing $2 \%$ Tween 80 ). All compounds were prepared on the same day of the experiments and administered intraperitoneally (ip) in a volume of $1 \mathrm{~mL} / \mathrm{kg}$ body weight. The doses administered in experiments 1 and 2 were chosen on the basis of pilot studies conducted in our laboratory, taking 
into account previously published data $(5,16)$.

\section{Apparatus}

Elevated T-maze. The ETM was made of wood and had 3 arms of equal dimensions (50 x $12 \mathrm{~cm})$. One arm was enclosed by $40-\mathrm{cm}$ high walls and was arranged perpendicularly to two opposed open arms. The entire apparatus was elevated $50 \mathrm{~cm}$ above the floor. To avoid falls, the open arms were surrounded by a Plexiglas rim $1 \mathrm{~cm}$ high.

Open field. For experiment 1, the apparatus used to measure locomotion was a square wooden box $(60 \times 60$ $\mathrm{cm}$ ), with the floor divided into 9 equal parts, and walls 30 $\mathrm{cm}$ high.

For experiment 2, the apparatus used was a round arena $(60 \times 60 \mathrm{~cm})$, with the floor divided into 16 parts, and walls $50 \mathrm{~cm}$ high.

Luminosity at the level of the maze arms or the open field center was 60 lux. After each experimental session, the models were cleaned with a $10 \%$ ethanol solution.

\section{Procedure}

Animals were injected ip with the EO from chemotype II (12.5 and $25 \mathrm{mg} / \mathrm{kg}),(\mathrm{R})-(-)$-carvone (25 mg/kg), DZP (2 $\mathrm{mg} / \mathrm{kg}$ ), or vehicle daily for 14 consecutive days. On the 13th day, each animal was pre-exposed to one of the open arms of the ETM for 30 min immediately before treatment. It has been shown that pre-exposure shortens escape latencies on the test day, rendering the escape test more sensitive to the effects of treatment (17). On the following day, 30 min after treatment, each animal was placed at the distal end of the enclosed arm of the ETM facing the intersection of the arms. The time taken by the rat to leave this arm, with all four paws, was recorded (baseline latency). Avoidance 1 and 2 were measured in the same way as baseline latency at 30-s intervals, during which animals were placed in a Plexiglas cage to which they had been previously habituated. Following avoidance training (30 s), rats were placed at the end of one of the open arms of the ETM and the time taken to leave this arm with all paws was recorded for three consecutive times with 30-s intertrial intervals (escape 1, 2, and 3). Immediately after being tested in the ETM, each animal was placed for $5 \mathrm{~min}$ in the open field for further evaluation of locomotor activity. During this time, the total number of lines crossed and the frequency of rearings were measured.

\section{Statistical analysis}

Repeated measures analysis of variance (ANOVA) was used to analyze avoidance and escape measurements, with treatment as the independent factor and trials as the dependent factor. In the case of significant effects of treatment or of the treatment versus trial interaction, data were analyzed by the Duncan post hoc test. The open field results were submitted to one-way ANOVA followed by the Duncan post hoc test. In all cases, a value of $\mathrm{P} \leq 0.05$ was considered to be significant.

\section{Results}

Table 1 shows the main components of chemotype II. It can be seen through CG:MS analysis that carvone accounts for approximately $55 \%$ and limonene for $23 \%$ of the composition of this chemotype.

\section{Experiment 1 - Effects of chemotype II}

The upper panel in Figure 1 shows the anxiolytic effects of treatment with chemotype II from LA and with DZP on ETM avoidance measurements. Repeated measures ANOVA showed a significant effect of treatment $(F(3,25)$ $=3.81 ; \mathrm{P}=0.022)$ and treatment versus trial interaction $(F(6,50)=3.54 ; P=0.005)$, but no effect of trials $(F(2,50)$ $=2.39 ; \mathrm{P}=0.102)$. The Duncan post hoc test showed that all treatment groups were significantly different from the control group in avoidance $2(P<0.05)$.

The lower panel in Figure 1 shows absence of effects of the same treatments on one-way escape in the ETM. Repeated measures ANOVA showed a significant effect of trials $(F(2,50)=9.89$; $P<0.001)$, but no effects of treat-

Table 1. Constituents of chemotype II from Lippia alba (Mill) N.E.

\begin{tabular}{lrcc}
\hline Substance & $\begin{array}{c}\text { Retention } \\
\text { time }\end{array}$ & $\begin{array}{c}\text { Kovats } \\
\text { index }\end{array}$ & $\begin{array}{c}\text { Relative } \\
\text { percentage (\%) }\end{array}$ \\
\hline Alpha-thujene & 3.37 & 924 & 0.28 \\
Alpha-pinene & 3.48 & 928 & 0.21 \\
Sabinene & 4.29 & 956 & 2.98 \\
Myrcene & 4.68 & 970 & 0.46 \\
Limonene & 5.69 & 1005 & 23.13 \\
Beta-ocimene (Z) & 6.11 & 1020 & 0.43 \\
Gamma-terpinene & 6.62 & 1038 & 0.70 \\
Terpinen-4-ol & 9.90 & 1152 & 0.22 \\
Carvone & 12.53 & 1244 & 54.57 \\
Isopiperitenone & 15.23 & 1339 & 0.97 \\
Beta-bourbonene & 16.45 & 1381 & 0.73 \\
Beta-cubebene & 16.67 & 1389 & 0.26 \\
Beta-elemene & 16.74 & 1391 & 0.28 \\
Caryophyllene (E) & 17.52 & 1419 & 0.34 \\
Aromadendrene Allo & 18.80 & 1463 & 0.26 \\
Alpha-muurolene & 19.55 & 1490 & 4.84 \\
Gamma-cadinene & 19.93 & 1503 & 0.24 \\
Geracrene A & 20.20 & 1500 & 0.41 \\
Bulnesol & 21.68 & 1564 & 2.14 \\
\hline
\end{tabular}

Kovats index is a logarithmic scale on which the adjusted retention time of a peak is compared with those of unbranched alkanes. The relative percentage refers to the area calculated under the peak for that specific compound with respect to the total peak area. 

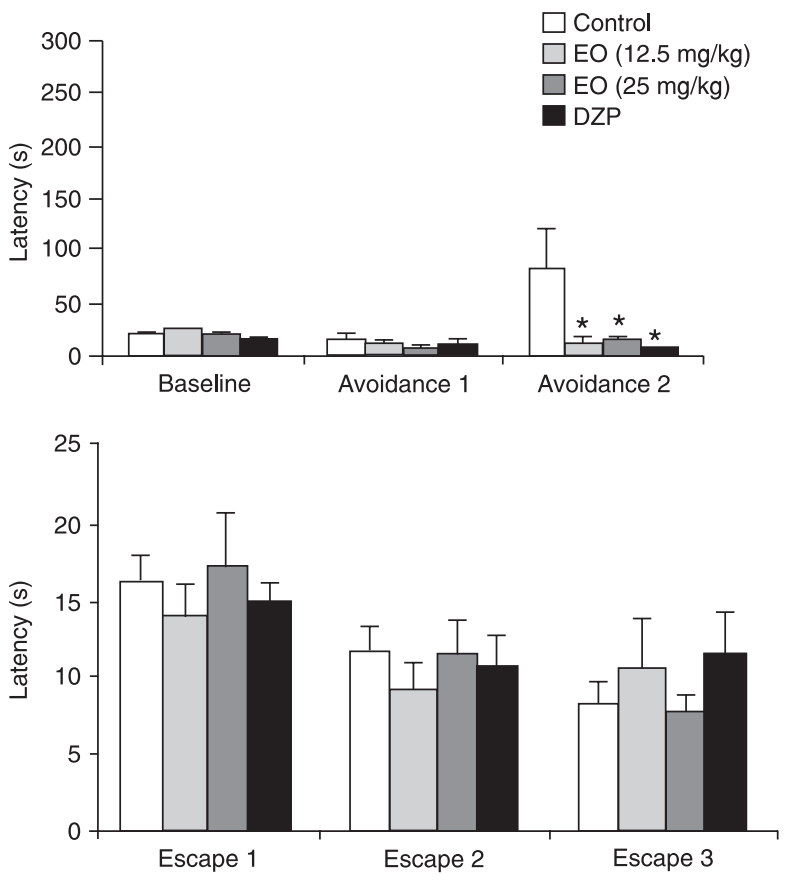

Figure 1. Effects of repeated daily treatment (14 days) with chemotype II from Lippia alba and with $2 \mathrm{mg} / \mathrm{kg}$ diazepam (DZP) on avoidance (upper panel) and escape measurements (lower panel) in the elevated T-maze. EO = essential oil. Control $(\mathrm{N}=8) ; 12.5 \mathrm{mg} / \mathrm{kg}$ EO $(\mathrm{N}=7) ; 25 \mathrm{mg} / \mathrm{kg}$ EO $(\mathrm{N}=6) ; \mathrm{DZP}(\mathrm{N}=$ 8). Data are reported as means \pm SEM. ${ }^{*} \mathrm{P}<0.05$ compared to control (ANOVA followed by the Duncan post hoc test).

ment $(F(3,25)=0.12 ; P=0.948)$ or treatment versus trial interaction $(F(6,50)=0.707 ; P=0.645)$.

One-way ANOVA showed that locomotor activity was not changed by drug administration. Neither the number of rearings $(F(3,25)=0.811 ; P=0.50)$ nor the number of crossings $(F(3,25)=0.793 ; P=0.509)$ were altered by treatment with chemotype II from LA or with DZP (data not shown).

\section{Experiment 2 - Effects of (R)-(-)-carvone}

The upper panel in Figure 2 illustrates the anxiolytic effects of treatment with (R)-(-)-carvone and DZP on ETM avoidance measurements. Repeated measures ANOVA showed a significant effect of trials $(F(2,50)=5.43$; $P=$ $0.007)$, treatment $(F(2,25)=19.79 ; P<0.001)$ and treatment versus trial interaction $(F(4,50)=6.24 ; P<0.001)$. The Duncan post hoc test showed that (R)-(-)-carvone was significantly different from the control group in avoidance 1 and that DZP was significantly different from the control group in avoidance 1 and $2(P<0.05)$.

The lower panel in Figure 2 shows absence of effects of the same treatments on one-way escape in the ETM. Repeated measures ANOVA showed a significant treatment versus trial interaction $(F(4,50)=2.93 ; P=0.03)$, but no ef-
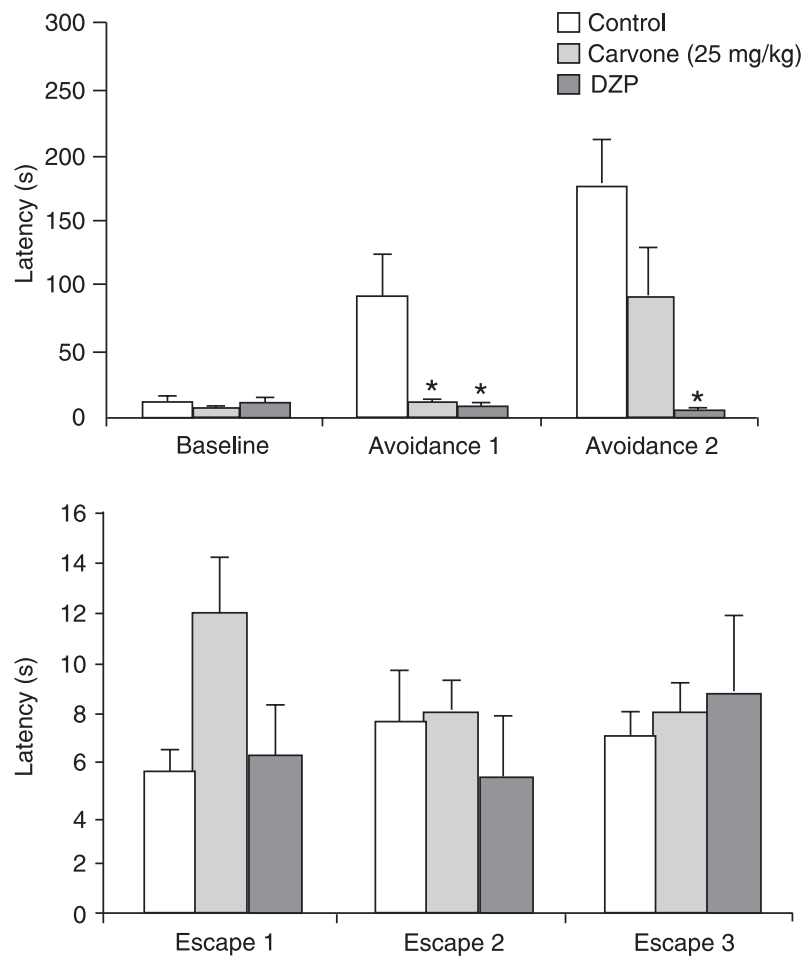

Figure 2. Effects of repeated daily treatment (14 days) with (R)(-)-carvone and with $2 \mathrm{mg} / \mathrm{kg}$ diazepam (DZP) on avoidance (upper panel) and escape measurements (lower panel) in the elevated Tmaze. Control ( $\mathrm{N}=12) ; 25 \mathrm{mg} / \mathrm{kg}(\mathrm{R})-(-)$-carvone $(\mathrm{N}=8)$; DZP ( $\mathrm{N}$ $=8)$. Data are reported as means \pm SEM. ${ }^{*} P<0.05$ compared to control (ANOVA followed by the Duncan post hoc test).

fect of trials $(F(2,50)=0.215 ; P=0.81)$ or treatment $(F(2,25)$ $=0.114 ; \mathrm{P}=0.89)$. The Duncan post hoc test showed that neither (R)-(-)-carvone nor DZP were significantly different from the control group in any trial.

Again, one-way ANOVA showed that locomotor activity was not changed. Neither the number of rearings $(F(2,25)=$ $2.49 ; P=0.10)$ nor the number of crossings $(F(2,25)=0.31$; $P=0.74)$ were altered by treatment with $(R)-(-)$-carvone or with DZP (data not shown).

\section{Discussion}

The results of the present study showed that repeated treatment with chemotype II from LA at the two doses administered (12.5 and $25 \mathrm{mg} / \mathrm{kg}$, ip) decreased ETM avoidance latencies, an anxiolytic effect. This same result was also observed with (R)-(-)-carvone and with the reference drug DZP. Escape measurements, on the other hand, were not modified by any of the treatments administered. Since the responses measured in the open field were not altered by treatment, it is possible to state that the anxiolytic effects observed are independent of locomotor alterations.

Our results are in agreement with previous reports of 
anxiolytic effects after acute treatment with higher doses (100 and $200 \mathrm{mg} / \mathrm{kg}$, ip) of chemotype II in another animal model of anxiety, the elevated plus-maze (5). As observed in the present study, there were no changes in the number of crossings in the open field, although the dose of $200 \mathrm{mg} /$ $\mathrm{kg}$ altered the number of rearings, indicating a possible neurosedative action in this dose range.

Differently from the elevated plus-maze, which, as mentioned, has been considered to be a mixed animal model of anxiety $(8,9)$, the ETM allows the measurement of two behavioral defensive responses specifically related to anxiety disorders found in clinical settings. In this respect, one of the main observations of the present study was that chemotype II acted selectively on inhibitory avoidance in clinical terms related to GAD (11-14). This selective profile of action may also explain the controversial effects observed with $\operatorname{LA}(6,7)$. For instance, it is possible that the lack of anxiolysis of some of the isolated constituents previously tested (7) reflects the lack of effect of LA on escape responses from the open arms of the plus-maze. Thus, further studies performed with different chemotypes of LA and other main constituents in more selective animal models of anxiety, in particular models that measure GAD-related responses (see Ref. 10), are still warranted.

In light of our present results, a role for carvone, the major constituent of chemotype II, was also suggested. In experiment 2, we tested the effects of repeated treatment with (R)-(-)-carvone, which in another study had shown a more potent neurosedative activity than the enantiometer (S)-(+)-carvone (16). Our results showed that (R)-(-)carvone decreased avoidance 1 latencies in the same way as DZP, without altering escape performance. The effect of (R)-(-)-carvone seems to be weaker than that of DZP, at least at the dose administered, since the latter drug also altered avoidance 2. It is interesting to point out that an anxiolytic effect of carvone had been previously proposed by Mora et al. (18). These authors investigated the anxiolytic and neurosedative effects in different animal models of a hydroalcoholic extract of Aloysia polystachya (Griseb.), a plant of the Verbenaceae family that is widely distributed in subtropical regions of South America and that contains carvone as a major constituent.

In fact, previous studies have shown that carvone, a monoterpene ketone of the terpenes and the main active ingredient of essential oils used in folk medicine and in phytotherapy as sedatives or tranquilizers, acts as a potent depressor of the central nervous system $(16,19)$. For instance, Buchbauer et al. (19) showed that the inhalation of two enantiomers of carvone ((S)-(+)-carvone and (R)-(-)-carvone) decreases locomotor activity in mice. A more recent study (16) indicated that the ip administration of these same enantiomers causes different depressant effects in mice, such as decreases in ambulation and in the reaction to touch, palpebral ptosis, and increases in sedation. Also, both enantiomers significantly potentiated pentobarbital sleeping time and increased the latency of convulsions induced by pentylenetetrazole and picrotoxin in a way similar to the reference drug DZP (16). Taking into account the depressant effects of carvone and the proposed mechanism of action for other monoterpene compounds (20), de Sousa et al. (16) suggested that carvone possibly interacts with GABAA receptors in the brain after crossing the blood-brain barrier. In the light of our present observations, this fact makes sense. It is possible that carvone inhibits neurons, which modulate behavioral inhibition (i.e., avoidance responses) in brain areas such as the amygdala and the septo-hippocampal system, structures that are activated in approach-avoidance conflict situations (10) (such as the one present when the animal is placed in the enclosed arm of the ETM).

In conclusion, the present results showed that repeated treatment with chemotype II from LA exerts anxiolytic-like effects on a specific subtype of defensive behavior that has been related to GAD in humans. The same was observed with (R)-(-)-carvone. Thus, it is possible that carvone, the main constituent of chemotype II, is one of the plant's constituents responsible for its therapeutic actions on anxiety.

\section{Acknowledgments}

We are grateful to Dr. Glauce Socorro de Barros Viana (Faculdade de Medicina de Juazeiro do Norte and Universidade Federal do Ceará) for kindly providing the essential oil, Dr. Afrânio Aragão Craveiro (Parque de Desenvolvimento Tecnológico, PADETEC, Universidade Federal do Ceará) and Vanderlan da Silva Bolzani (Universidade Federal do Ceará) for ${ }^{1} \mathrm{H}-\mathrm{NMR}$ spectrum analysis, and José Simões de Andrade (Universidade Federal de São Paulo, Campus Baixada Santista) for technical assistance. Research supported by CNPq and FAPESP.

\section{References}

1. Hennebelle T, Sahpaz S, Joseph H, Bailleul F. Ethnopharmacology of Lippia alba. J Ethnopharmacol 2008; 116: 211222.

2. Pino Alea JA, Ortega Luis AG, Rosado Pérez A, Rodríguez Jorge M, Baluja R. Composición y propriedades antibacterianas del aceite esencial de Lippia alba. Rev Cubana Farm
1998; 30: 0-10.

3. Holetz FB, Pessini GL, Sanches NR, Cortez DA, Nakamura CV, Filho BP. Screening of some plants used in the Brazilian folk medicine for the treatment of infectious diseases. Mem Inst Oswaldo Cruz 2002; 97: 1027-1031.

4. Abad MJ, Bermejo P, Villar A, Sanchez Palomino S, Carras- 
co L. Antiviral activity of medicinal plant extracts. Phytother Res 1997; 11: 198-202.

5. Matos FJA, Machado MIL, Craveiro AA, Alencar JW. Essential oil composition of two chemotypes of Lippia alba grown in Northeast Brazil. J Essent Oil Res 1996; 8: 695-698.

6. Vale TG, Matos FJ, de Lima TC, Viana GS. Behavioral effects of essential oils from Lippia alba (Mill.) N.E. Brown chemotypes. J Ethnopharmacol 1999; 67: 127-133.

7. do Vale TG, Furtado EC, Santos JG Jr, Viana GS. Central effects of citral, myrcene and limonene, constituents of essential oil chemotypes from Lippia alba (Mill.) N.E. Brown. Phytomedicine 2002; 9: 709-714.

8. Handley SL, McBlane JW. 5HT drugs in animal models of anxiety. Psychopharmacology 1993; 112: 13-20.

9. Rodgers RJ, Dalvi A. Anxiety, defence and the elevated plusmaze. Neurosci Biobehav Rev 1997; 21: 801-810.

10. Graeff FG, Zangrossi H Jr. Animal models of anxiety. In: D'Haenen D, Den Boer JA, Willner P (Editors), Biological psychiatry. London: John Wiley \& Sons; 2002. p 1-15.

11. Viana MB, Tomaz C, Graeff FG. The elevated T-maze: a new animal model of anxiety and memory. Pharmacol Biochem Behav 1994; 49: 549-554.

12. Graeff FG, Netto CF, Zangrossi H Jr. The elevated T-maze as an experimental model of anxiety. Neurosci Biobehav Rev 1998; 23: 237-246.

13. Teixeira RC, Zangrossi H, Graeff FG. Behavioral effects of acute and chronic imipramine in the elevated T-maze model of anxiety. Pharmacol Biochem Behav 2000; 65: 571-576.

14. Poltronieri SC, Zangrossi H Jr, de Barros V. Antipanic-like effect of serotonin reuptake inhibitors in the elevated T-maze. Behav Brain Res 2003; 147: 185-192.

15. Nutt D. Anxiety and its therapy: Today and tomorrow. In: Briley M, File S (Editors), New concepts in anxiety. London: MacMillan Press; 1991. p 1-12.

16. de Sousa DP, de Farias Nobrega FF, de Almeida RN. Influence of the chirality of (R)-(-)- and (S)-(+)-carvone in the central nervous system: a comparative study. Chirality 2007; 19: 264-268.

17. Sena LM, Bueno C, Pobbe RL, Andrade TG, Zangrossi H $\mathrm{Jr}$, Viana MB. The dorsal raphe nucleus exerts opposed control on generalized anxiety and panic-related defensive responses in rats. Behav Brain Res 2003; 142: 125-133.

18. Mora S, Díaz-Veliz G, Millan R, Lungenstrass H, Quiros S, Coto-Morales T, et al. Anxiolytic and antidepressant-like effects of the hydroalcoholic extract from Aloysia polystachya in rats. Pharmacol Biochem Behav 2005; 82: 373-378.

19. Buchbauer G, Jäger W, Gruber A, Dietrich H. R-(+)- and S-(-)-carvone: Influence of chirality on locomotion activity in mice. Flavour Frag J 2005; 20: 686-689.

20. Granger RE, Campbell EL, Johnston GA. (+)-And (-)-borneol: efficacious positive modulators of GABA action at human recombinant alpha1beta2gamma2L $\mathrm{GABA}(\mathrm{A})$ receptors. Biochem Pharmacol 2005; 69: 1101-1111. 